\title{
Degradation Kinetics of 4-chlorophenol Wastewater and Toxicity Evolution in the Process of Electrochemical Reduction- Oxidation Coupling under Three-Electrode Diaphragm System
}

\author{
Dandan $\mathrm{Xu}^{1}$, Yan Wang ${ }^{1}$, Hui Wang ${ }^{1, *}$, Zhaoyong Bian ${ }^{2, *}$ \\ ${ }^{1}$ College of Environmental Science and Engineering, Beijing Forestry University, Beijing 100083, PR \\ China \\ ${ }^{2}$ College of Water Sciences, Beijing Normal University, Beijing 100875, PR China \\ "E-mail: wanghui@bjfu.edu.cn, bian@bnu.edu.cn
}

doi: $10.20964 / 2017.07 .66$

Received: 7 April 2017 / Accepted: 14 May 2017 / Published: 12 June 2017

\begin{abstract}
Electrochemical reduction-oxidation process was used to degrade simulated paper wastewater using three-electrode diaphragm system with $\mathrm{Pd}-\mathrm{Fe} /$ graphene gas-diffusion cathode. The degradation efficiency and toxicity variation assessment were analyzed during the 4-chlorophenol (4-CP) wastewater degradation process. The 4-CP wastewater was degraded effectively and the removal efficiency of chemical oxygen demand (COD) in simulated paper wastewater was $78.2 \%$ (anodic), $80.7 \%$ (cathodic 1) and $81 \%$ (cathodic 2). The toxicity inhibition effect of two cathodic and anodic almost reached $100 \%, 100 \%$, and $81.0 \%$ at $120 \mathrm{~min}$, respectively. The comparison showed concentration for $50 \%$ of maximal effect $\left(\mathrm{EC}_{50}\right)$ of simulated paper wastewater increased with the raise of $\mathrm{EC}_{50}$ of 4-CP. The elimination of toxicity exhibited a hysteresis effect and a rise tendency within 60 min, which might be attributed to the formation of more toxic intermediates such as benzoquinone. A good kinetics model was used to predict degradation of 4-CP and two possible reaction pathways were proposed, featuring a series of steps including cleavage of $\mathrm{C}-\mathrm{Cl}$ bond, hydrodechlorination, hydroxyl radical addition and oxidation. The $\mathrm{Pd}-\mathrm{Fe} / \mathrm{graphene}$ gas-diffusion cathode was promising to dechlorination and detoxication of simulated paper wastewater containing 4-CP.
\end{abstract}

Keywords: simulated paper wastewater; 4-chlorophenol; reduction-oxidation process; kinetics; toxicity

\section{FULL TEXT}

(C) 2017 The Authors. Published by ESG (www.electrochemsci.org). This article is an open access article distributed under the terms and conditions of the Creative Commons Attribution license (http://creativecommons.org/licenses/by/4.0/). 